\title{
Concomitant Medication Administration Dose
}

National Cancer Institute

\section{Source}

National Cancer Institute. Concomitant Medication Administration Dose. NCI Thesaurus.

Code C83160.

The dose of concomitant medication taken per administration. 